\title{
Comparison of a novel microcrystalline tyrosine adjuvant with aluminium hydroxide for enhancing vaccination against seasonal influenza
}

\author{
M. D Heath ${ }^{1 *}$, N. J. Swan ${ }^{1}$, A. C. Marriott ${ }^{2}$, N. J. Silman², B. Hallis², C. Prevosto ${ }^{2,3}$, K. E. Gooch ${ }^{2}$ and M. A. Skinner ${ }^{1}$
}

\begin{abstract}
Background: Vaccination against seasonal influenza strains is recommended for "high risk" patient groups such as infants, elderly and those with respiratory or circulatory diseases. However, efficacy of the trivalent influenza vaccine (TIV) is poor in many cases and in the event of an influenza pandemic, mono-valent vaccines have been rapidly developed and deployed. One of the main issues with use of vaccine in pandemic situations is the lack of a suitable quantity of vaccine early enough during the pandemic to exert a major influence on the transmission of virus and disease outcome. One approach is to use a dose-sparing regimen which inevitably involves enhancing the efficacy using adjuvants.
\end{abstract}

Methods: In this study we compare the use of a novel microcrystalline tyrosine (MCT) adjuvant, which is currently used in a niche area of allergy immunotherapy, for its ability to enhance the efficacy of a seasonal TIV preparation. The efficacy of the MCT adjuvant formulation was compared to alum adjuvanted TIV and to TIV administered without adjuvant using a ferret challenge model to determine vaccine efficacy.

Results: The MCT was found to possess high protein-binding capacity. In the two groups where TIV was formulated with adjuvant, the immune response was found to be higher (as determined by HAl titre) than vaccine administered without adjuvant and especially so after challenge with a live influenza virus. Vaccinated animals exhibited lower viral loads (as determined using RT-PCR) than control animals where no vaccine was administered.

Conclusions: The attributes of each adjuvant in stimulating single-dose protection against a poorly immunogenic vaccine was demonstrated. The properties of MCT that lead to the reported effectiveness warrants further exploration in this and other vaccine targets - particularly where appropriate immunogenic, biodegradable and stable alternative adjuvants are sought.

Keywords: Vaccine, Influenza, Adjuvant, Microcrystalline tyrosine, Aluminum, Ferret

\section{Background}

Influenza A virus infections (IAV) in humans have been described for well over 100 years and certainly long before the major pandemic that occurred in 1918 with the H1N1 strain of virus [1]. Influenza viruses comprise an RNA genome which is formed of 8 different segments, thus providing ample opportunity for segments to be easily transferred between different virus strains [2]. This

\footnotetext{
* Correspondence: matthew.heath@allergytherapeutics.com

'Allergy Therapeutics Ltd, Dominion Way, West Sussex BN14 8SA, UK

Full list of author information is available at the end of the article
}

transfer or reassortment brings about the phenomenon of antigenic shift where influenza viruses undergo a major change in their antigenic structure as a consequence of segment-swapping and are able to transmit freely within an essentially immunologically naïve population. More limited changes in the influenza virus antigenic structures occur as a result of antigenic drift; this occurs as a consequence of minor amino acid substitutions which result from transcription and translation errors of the RNA genome [3]. The mutation rate was determined for the recent H1N1 2009 pandemic virus 
across two influenza seasons and was found to be $10^{-3}$ per nucleotide site per year [4].

The first of these factors (antigenic shift) is the key property of the virus which is considered during pandemic preparedness, however at least two of these other four 'signature' factors should be further investigated, these are, the higher observed transmissibility and the higher mortality in younger populations [3]. This was exactly the scenario with the recent pandemic caused by the "new" H1N1 virus in 2009 where infection with pandemic influenza virus resulted in a range of symptoms in different people which varied from mild, sub-clinical infection to severe viral pneumonia requiring hospitalisation and specialist intensive care [5]. The increased transmissibility is almost certainly a result of the emergence of an effectively "new" virus by antigenic shift which is then able to infect a naïve population; younger members of the population being more likely to be immunologically naïve having never been exposed to similar viruses, whereas older subjects may be more protected due to immunological memory [6].

Because of these constant evolutionary changes, leading to antigenically novel strains and subtypes emerging within the human population, seasonal vaccines against IAV viruses have to be updated on an annual basis. A recent study on the effectiveness of influenza vaccination indicated that effectiveness of the vaccine ranged from $36 \%$ to $58 \%$ with greater effectiveness against H1N1 strains than H3N2 viruses [7]. Indeed, recent data indicate that during the winter of 2014-15 in the Northern Hemisphere, the H3N2 circulating virus strains were significantly different from the vaccine strain and resulted in much lower or zero effectiveness against these strains [8]. One approach to the improvement of efficacy of influenza vaccines has been the evaluation of adjuvants to promote both improved immunogenicity as well as dose sparing in pandemic situations.

Seasonal influenza vaccines are widely produced and used and are formulated as a trivalent (A/H1N1, $\mathrm{A} / \mathrm{H} 3 \mathrm{~N} 2$ and $\mathrm{B}$ ), formalin-inactivated and split virus preparation, typically containing $15 \mu \mathrm{g}$ of each haemagglutinin (HA) protein in a standard adult dose. Although widely used, the trivalent influenza vaccine (TIV) is known to have relatively poor and variable effectiveness [9]. In the naïve ferret model, non-adjuvanted TIV shows poor efficacy against intranasal challenge with homologous virus. Ferret vaccine efficacy studies have typically used the standard adult human dose in each ferret, either as two or more doses [10,11], or formulated with adjuvant [12, 13].

For almost a century, salts of aluminium (hydroxide and phosphate) were the only approved adjuvants in humans [14]. An often described limitation of aluminium adjuvants relates to the non-biodegradable nature and the stimulation of so-called T-helper type 2 (Th2) as opposed to Th1 immune responses, which affect the type and quality of antibody responses produced [15]. Therefore the goals of new adjuvants in combination with an influenza target vaccine, are (i) to facilitate recognition of the antigen, thereby facilitating the use of smaller doses (dose sparing) of antigen (ii) to be biodegradable and biocompatible, (iii) to be without toxic or inflammatory side effects, (iv) to trigger protective Th1-like immune responses as well as antigen-neutralising antibodies, thereby increasing the proportion of subjects that become protectively immunised and (v) increase seroconversion rates in populations with reduced responsiveness (i.e. infants and the elderly).

Aluminium hydroxide has been used as a depot candidate in many formulations to date including influenza vaccine candidates $[16,17]$, however, it could be limited as an influenza candidate for which annual vaccination may favour the use of a depot adjuvant with biodegradable properties ensuring clearance prior to revaccination, in addition to adjuvant candidates which stimulate more effective Th1 T-cell responses [18]. Allergy Therapeutics (AT) has pioneered the concept of a slow-release licensed depot adjuvant formulation for allergy vaccines with a proven safety and efficacy profile $[19,20]$. Whereas other manufacturers still use mainly aluminium hydroxide (alum), AT uses Micro-Crystalline Tyrosine (MCT), a natural amino acid formulation, in its vaccine formulations. MCT exhibits a high adsorptive power for proteins at neutral $\mathrm{pH}$, it enhances the induction of IgG antibodies with no unusual propensity to stimulate IgE, has a half-life of $48 \mathrm{~h}$ at the site of injection while delivering a sustained release of antigens for prolonged immune exposure and, unlike alum, it is fully metabolised within the body $[19,21,22]$. Its mechanistic pathways as an adjuvant are currently sought and an ongoing study has recently highlighted induction of specific $\mathrm{T}$ cell responses. Measurements investigating specific $\mathrm{T}$ cell responses, DC activation and expression markers in challenge models are ongoing (Prof. Thomas M. Kuendig, University of Zurich, personal communication, June 2016). Moreover, MCT offers a compatible mode of adsorption with 2nd generation immunomodulators (i.e. TLR agonists). As such, has been combined successfully with Monophosphoryl Lipid A (MPL) which offers a novel ultra-short-course allergy immunotherapy as a named patient product [23], of which, has recently completed a successful phase II dose ranging trial in Europe [24], while different iterations (allergy indications) of the platform are in current clinical development both in the EU and US. MPL is a TLR-4 agonist able to modulate Th1 immune reactivity, its physicochemical and biological compatibility with MCT has been described previously [19-22]. 
The aims of this study were to compare the efficacy of TIV with alum (Alhydrogel) to TIV with MCT in protecting ferrets against a low-dose challenge with a clinically relevant human $\mathrm{H} 1 \mathrm{~N} 1$ virus. The low-dose challenge model has been shown to be more sensitive in demonstrating antiviral activity, while at the same time producing a larger amount of virus shedding and more representative disease kinetics when compared to the traditional high $\left(10^{6} \mathrm{pfu}\right)$ dose ferret challenge model [25].

\section{Methods}

\section{Virus and vaccines}

Influenza A/California/04/09 virus (H1N1) was propagated in MDCK cells. Viral genomic RNA from the virus stock was fully sequenced and showed no differences from the published A/California/04/09 sequence. The vaccine used was Inactivated Influenza Vaccine (Split Virion) BP from Sanofi Pasteur, containing antigens from the viruses recommended for the 2014-15 season. Each $0.5 \mathrm{ml}$ dose contained $45 \mu \mathrm{g}$ HA protein, $15 \mu \mathrm{g}$ each from the $\mathrm{H} 1 \mathrm{~N} 1, \mathrm{H} 3 \mathrm{~N} 2$ and $\mathrm{B}$ virus components. The H1N1 component was from the A/California/07/ 09-derived vaccine strain NYMC X-179A, which is antigenically indistinguishable from the challenge strain. The other components were H3N2 (A/Texas/50/12-like) and $\mathrm{B} /$ Massachusetts/2/12.

\section{Adjuvants}

Alhydrogel (2\% $w / v$ suspension of aluminium hydroxide; Invivogen, USA) was mixed with vaccine in the ratio $43 \mu \mathrm{l}$ Alhydrogel per $1 \mathrm{ml}$ vaccine plus $1 \mathrm{ml}$ buffered saline, $\mathrm{pH} 6$, containing $0.5 \% \mathrm{w} / v$ phenol. Micro-crystalline tyrosine (MCT) was manufactured at Allergy Therapeutics Ltd, Worthing, UK, as a $4 \% w / v$ suspension in buffered saline, $\mathrm{pH} 6$, containing $0.5 \% \mathrm{w} / \mathrm{v}$ phenol and was mixed $1.05: 1$ by volume with vaccine ( $2 \%$ target concentration). For both adjuvants, the suspension was mixed at room temperature for $1 \mathrm{~h}$ prior to vaccination.

\section{Sample preparation; MCT adsorption capacity}

$300 \mu \mathrm{l}$ of $100 \mu \mathrm{g} / \mathrm{ml} \mathrm{H1N1}$ antigen (Influenza A H1N1 (A/Puerto Rico/8/1934), Haemagglutinin from SinoBiologicals Inc. was mixed with $700 \mu \mathrm{l}$ of $2 \% w / v$ tyrosine blank (MCT) for $1 \mathrm{~h}$ at room temperature, to give a target $\mathrm{H} 1 \mathrm{~N} 1$ concentration of $30 \mu \mathrm{g} / \mathrm{mL}$, followed by centrifugation of the sample for $4 \mathrm{~min}$ at $3 \times \mathrm{g}$. An identical process was followed to produce the two controls, one control (control A) comprised antigen + DPBS and a second control (Control B) contained MCT alone. Both control groups are representative of Group A and Group $B$ vaccines used in this study.

The protein concentration present in the supernatant from the sample and both controls were determined using Bradford reagent [26], with the exception that the standard curve was prepared in DPBS to remove any possibility of interference from different buffers.

ELISA analysis confirmed $>95 \%$ adsorption of the antigen by MCT (Fig. 1).

\section{ELISA analysis}

The supernatant from the sample and controls prepared as described in MCT adsorption capacity, were diluted $1: 10,000$, according to the manufacturer's instructions (Sino biological Inc.). The supernatant from the MCT control (control B) was loaded undiluted. Sample and controls were analysed as per the manufacturer's instructions.

In summary, polystyrene microplates were pre-coated with a mouse monoclonal antibody against $\mathrm{H} 1 \mathrm{~N} 1$, the plate was washed. A standard curve of $\mathrm{H} 1 \mathrm{~N} 1$ protein was prepared covering the range $46-3000 \mathrm{pg} / \mathrm{ml}$ and the samples loaded on to the ELISA plate. The plate was incubated for $2 \mathrm{~h}$ at room temperature then washed. The detection antibody was added and the plate incubated for a further $1 \mathrm{~h}$ at room temperature. The plate was washed and substrate solution added. The plate was incubated for a further $20 \mathrm{~min}$ and stop solution was added and the UV absorbance was analysed using a plate reader (Envision, Perkin-Elmer) at $450 \mathrm{~nm}$. The concentrations of samples was analysed with comparison to the results obtained for the standard curve.

\section{Ferret study}

Eighteen ferrets (Mustela putorius furo) were obtained from Highgate Farm, with starting weights between 0.78-1.79 kg. The experimental animal work described here was scrutinized and approved by the Animal Welfare and Ethical Review Body of Public Health England (Porton), as required by the UK Home Office Animals (Scientific Procedures) Act, 1986. The premises in which the work was conducted are approved under Home Office Certificate of Designation PCD70/1707. A serum sample from each animal was screened for absence of antibodies to influenza A virus by HAI prior to commencement of the study. Animals received an intra-muscular vaccination of $1 \mathrm{ml}$ total volume, divided equally between the two hind legs. Twenty-one days later, sedated ferrets were challenged by intra-nasal instillation of $0.2 \mathrm{ml}$ virus, containing $100 \mathrm{PFU}$ A/California/04/09, divided between the two nares. Nasal wash liquids were collected daily thereafter, using $2 \mathrm{ml}$ PBS per ferret. The cell content of the nasal wash fluid was determined by haemocytometry. Animals were euthanised 5 or 10 days post-challenge for viral and histological tissue analysis. 


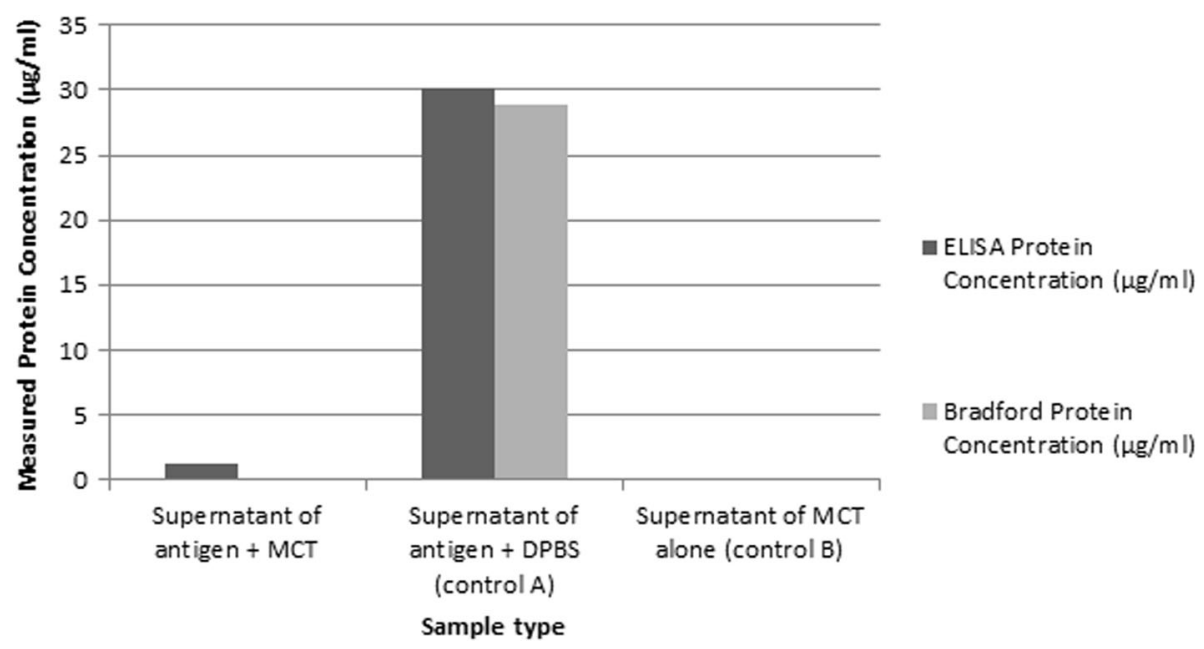

Fig. 1 Total and specific protein concentrations of H1N1 measured by ELISA and Bradford reagent

\section{Serum antibodies}

Influenza $\mathrm{H} 1 \mathrm{~N} 1$-specific antibodies were titrated by haemagglutination inhibition (HAI), and neutralizing antibodies were titrated by microneutralization $(\mathrm{MN})$ as described elsewhere [27].

\section{Virus load}

Infectious virus in nasal wash fluid was determined by plaque assay on MDCK cells. Respiratory tract tissues were collected into RNAlater solution (Sigma-Aldrich, UK) for RNA extraction. Quantification of the extracted viral $M$ gene RNA was performed using real-time qRTPCR, employing a synthetic T7 transcript of the A/California/04/09 $M$ gene as a standard of known copynumber [25].

\section{Statistical methods}

Non-parametric tests (Mann-Whitney U-test) and 1-way ANOVA were performed using Minitab 16 software. Tests were considered statistically significant where $p \leq 0.05$.

\section{Results}

\section{Antibody responses to vaccination}

Ferrets were divided into 4 groups for vaccination as follows: (A) TIV unmodified $(n=3)$; (B) TIV formulated with MCT $(n=6)$; (C) TIV formulated with Alhydrogel $(n=6)$; and (D) mock-vaccinated with PBS $(n=3)$. At 19 days post-vaccination serum samples were collected for determination of influenza H1N1-specific antibodies by HAI and MN tests (Fig. 2). Group mean HAI titres for groups $\mathrm{B}$ and $\mathrm{C}$ were higher than those for groups $\mathrm{A}$ and D on day 19 , although this trend was not statistically significant. In the ferret model an HAI titre of $\geq 20$ is widely considered to be sero-positive, as in the case of

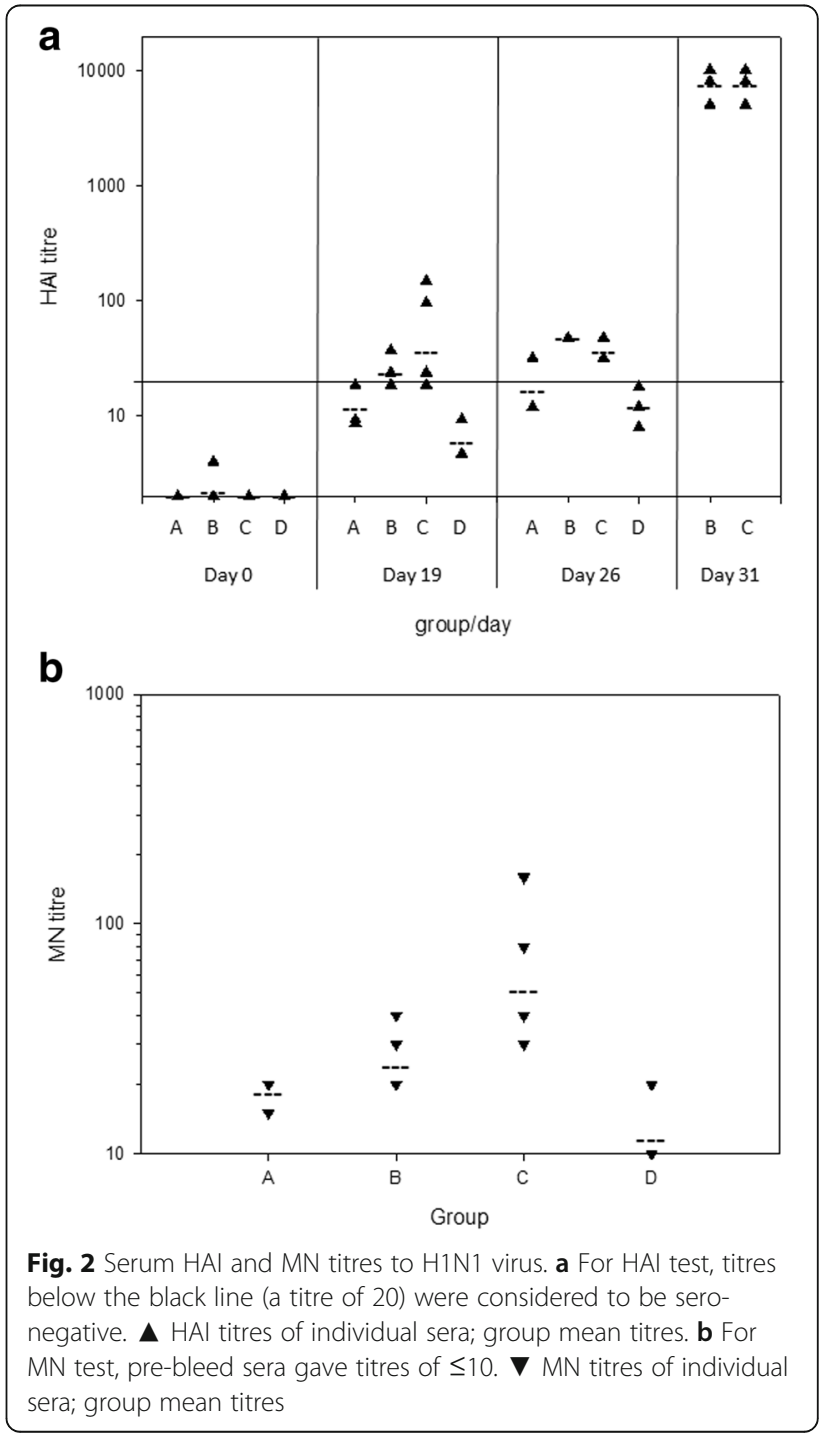


human sera $[28,29]$. No ferrets in groups A or D showed sero-conversion, whereas 4 of 6 ferrets in group $\mathrm{B}$ and 3 of 6 ferrets in group $\mathrm{C}$ were sero-positive following vaccination alone. Similarly, $\mathrm{MN}$ titres were higher for groups $\mathrm{B}$ and $\mathrm{C}$ (Fig. 2b), although this was not significant by 1 -way ANOVA $(p=0.085)$. HAI titres correlated well with the MN titres for individual ferrets $\left(R^{2}=0.93\right)$. Group $C$ showed a significantly higher mean MN titre than group B (Mann-Whitney test, $p=0.03$ ).

All animals were challenged with $\mathrm{H} 1 \mathrm{~N} 1$ virus via the intranasal route 21 days post-vaccination and terminal sera were collected from 3 ferrets per group on days 5 (all groups) and 10 (groups $\mathrm{B}$ and $\mathrm{C}$ only) postchallenge. HAI tests on the terminal sera showed a modest increase in group mean titres at day 26 ( 5 days postinfection) compared to day 19, but a much greater increase at day 31 (10 days post-infection) (Fig. 2a). Groups B and $C$ showed significantly higher mean titres than groups A and D on day 26 (1-way ANOVA, $p=0.002)$; there was no significant difference in HAI titre between groups $\mathrm{B}$ and $\mathrm{C}$ on either day.

\section{Protection against influenza infection}

Ferrets were monitored for signs of disease following intra-nasal challenge. All challenge groups showed weight loss in the 5 days following infection, with the greatest loss in unvaccinated group D (6.3\%), and the least in vaccinated group B (3.8\%). The differences between groups were not statistically significant (Additional file 1). The only clinical signs that were observed were sneezing and diarrhoea. The most frequent observation of sneezing was in group D and the least in group B; again the differences between the groups were not statistically significant. A sharp rise in viable cell concentration in nasal wash fluid has been used as a surrogate marker for the host response to influenza infection [25]. All groups showed a rise in cell count between days 2 and 3 post-infection (Fig. 3a). Infectious virus shedding was monitored by plaque assay of nasal wash fluids. All ferrets were found to shed infectious virus from their nasal cavities, with a peak on day 3 postinfection (Fig. 3b). Group C showed a lower mean titre on days 2 to 5 , but differences between groups were not statistically significant. Using area under the curve as an indication of total virus shedding, group $C$ shed significantly less virus over the course of the infection than group B (Mann-Whitney test, $p=0.04$ ). Virus shedding became undetectable in surviving animals by 8 days post-infection (Fig. 3b).

\section{Viral RNA replication in ferret tissues}

RNA was extracted from nasal turbinate, trachea and 3 lobes of the lung from each animal post-mortem. Viral RNA concentration (M gene) was determined by real-
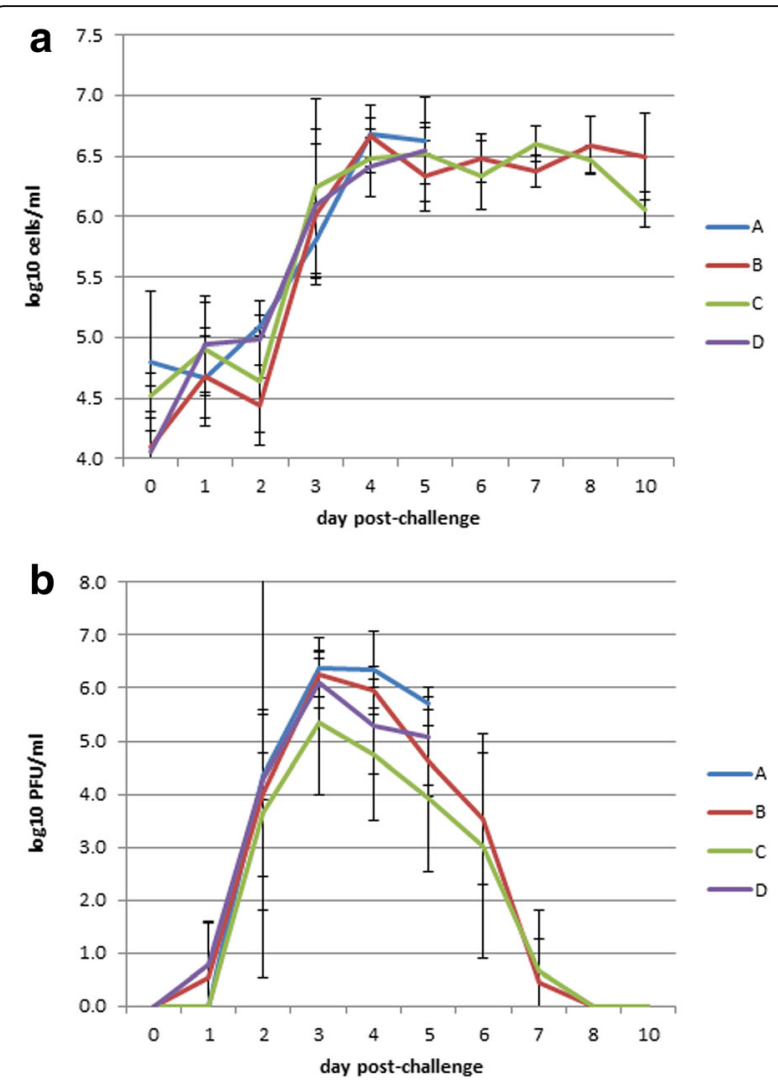

Fig. 3 Nasal wash viable cell concentration (a) and infectious virus titre (b). Samples without detectable virus were scored as 1 PFU/ml to allow plotting

time PCR and normalised for the amount of tissue extracted. As expected the vRNA levels dropped in all tissue types between days 5 and 10 post-challenge (Fig. 4). None of the vaccinated groups showed clear reductions in vRNA load in any of the tissues, relative to the unvaccinated group D, except that, when considering the combined lung samples for each animal, group A showed significantly lower vRNA loads than group D at 5 days postchallenge (Mann-Whitney test, $p=0.04$ ).

\section{Discussion}

This study provides a comparative analysis of efficacy using two established depot adjuvants in protecting against a low-dose challenge with a human H1N1 virus in a ferret model. Ferrets are considered the most representative model for studying influenza pathology since it has been extensively characterised and used for influenza vaccine development $[30,31]$.

Aluminium adjuvants induce robust antibody responses which make it suitable for use in vaccines that target pathogens, neutralised primarily by antibodies. Long-term success in the use of aluminium-adjuvanted vaccines targeting intracellular pathogens, in the context of protective efficacy, is less recognised and highlights 

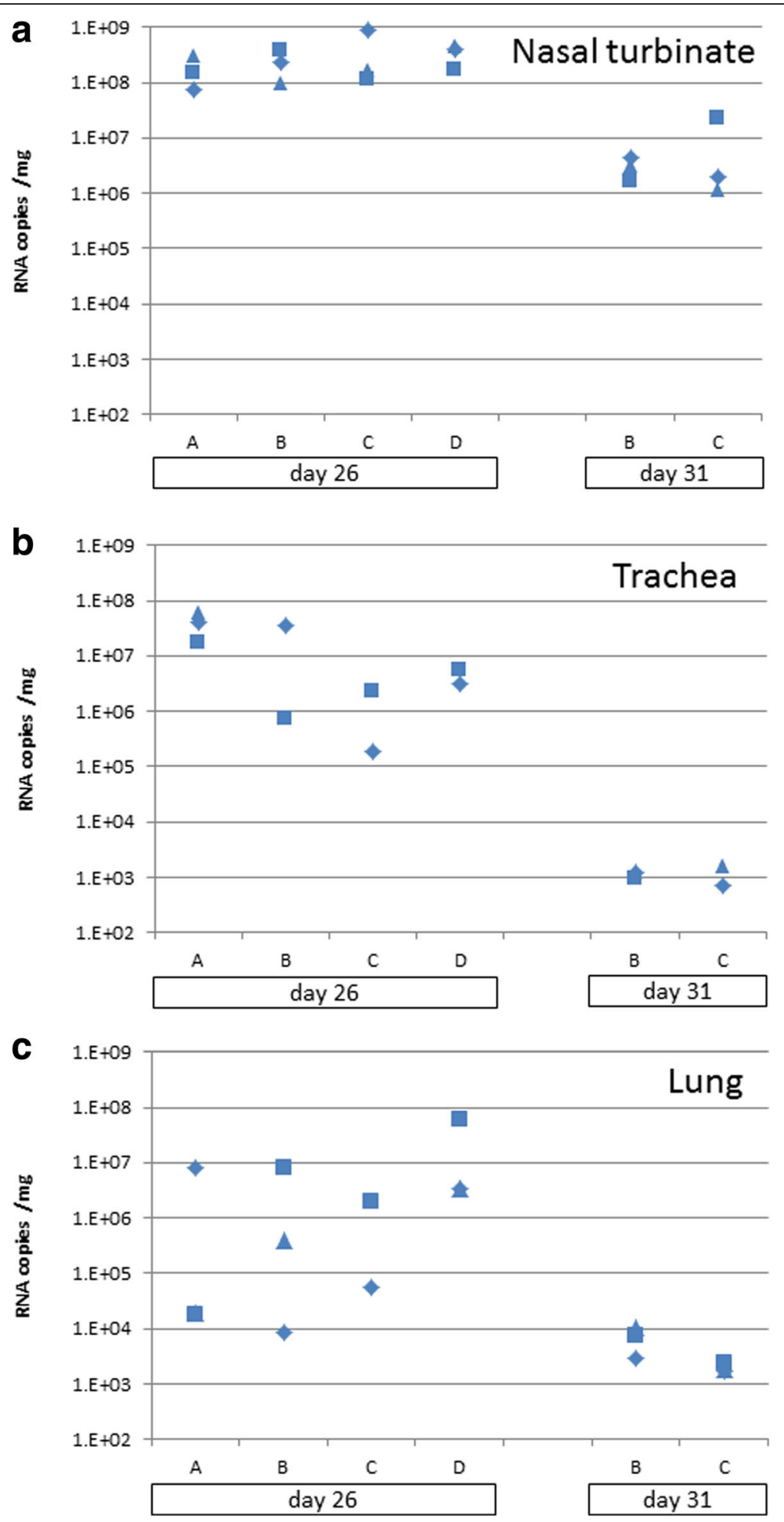

Fig. 4 Tissue RNA loads as copies of M gene RNA per mg tissue. a nasal turbinate's, $\mathbf{b}$ trachea, $\mathbf{c}$ lung. Panels a and $\mathbf{b}$ show titres of individual ferrets. In panel c, for each ferret 3 lung lobes were sampled and the mean was taken 
the limitations in providing protective efficacy in human populations that require robust Th1 T-cell responses, as a consequence of its function to preferentially induce Th2 cells [32].

Co-precipitates of micro crystalline tyrosine (MCT) and proteins have been extensively used and endorsed by health authorities for use as a depot adjuvant in longcourse allergen specific subcutaneous immunotherapy [19]. As a consequence, the use of MCT in infectious disease models and cancer is now being explored and is showing early promise [33].

The adsorption capacity of MCT was assessed independently since this adjuvant has not previously been formulated with an infectious disease target. Adsorption of infectious disease antigens to aluminium adjuvants is well documented has been shown to improve vaccine potency and stability [34]. The mode of action of an adjuvant can be influenced by the amount of antigen physically adsorbed to the adjuvant and, in some cases, considered to be an important aspect for their function [35]. As a consequence, The World Health Organisation has since recommended a figure of $>95 \%$ adsorption at $0.5 \%$ antigen loading levels in some indications [36] and the results presented herein (Fig. 1) confirm $>95 \%$ adsorption of MCT with the H1N1 target antigen. The aromatic ring of Tyrosine in its crystalline complex with a target offers an alternative predominant mechanism of adsorption to aluminium which is governed via ligand exchange between hydroxyl groups on the adjuvant and available phosphorylated groups of the antigen. A number of advantages may also exist in the use of MCT alone and in synergy within adjuvant system complexes. For example, in an adjuvant-adsorption study, Bell et al. (2015) characterised the compatible nature of MCT with a TLR4 agonist, inferring pi-chi interactions as a predominant mechanism of adsorption. Some TLR agonists and antigens do not readily adsorb to Aluminium, but may be more compatible with alternative formulations [37].

A single dose $(45 \mu \mathrm{g})$ of HA protein $(15 \mu \mathrm{g}$ each from the H1N1, H3N2 and B components) adjuvanted with either MCT (study group B) or aluminium hydroxide (study group C) was effective in generating a seropositive (HAI > 20) titre 2 days prior to challenge (19 days post-vaccination). An HAI titre of $>40$ is considered protective in human sera and by 26 days postvaccination ( 5 days post challenge), $3 / 3$ ferrets in group $\mathrm{B}$ (MCT), 1/3 ferrets in group C (Alum), and 0/3 ferrets in groups $\mathrm{A}$ and $\mathrm{D}$ showed HAI titres $>40$. However, 10 days post challenge a much greater increase in HAI titres was produced with no significant differences observed between the two adjuvanted groups.

Neutralizing antibody titres, determined 2 days prior to challenge, also showed a greater response in the two adjuvanted vaccine groups, $\mathrm{B}$ and $\mathrm{C}$, compared to the non-adjuvanted group $\mathrm{A}$, with alum adjuvant giving a higher mean titre. The close correlation of HAI and neutralization titres suggests that the two adjuvants were inducing functionally equivalent influenza-specific antibodies.

The intra-nasal challenge of ferrets with 100 PFU H1N1pdm09 virus has previously been used to demonstrate efficacy of both a defective influenza particle and of oral oseltamivir therapy $[25,38,39]$. It is well established that non-adjuvanted inactivated influenza vaccines perform very poorly in the ferret model $[10,11,40]$, so the low-dose challenge was chosen for this study in order to minimise the possibility of the virus infection overwhelming any immunity which had been induced. While no significant protection was observed following a single dose of vaccine, in terms of virus shedding or viral replication in the lungs, both alum and MCT adjuvants clearly induced levels of influenza-specific functional antibodies prior to infection which were not observed in the non-adjuvanted vaccine group. There was also a trend towards reduced disease (weight loss and nasal symptoms) in the MCT-adjuvanted group B.

The addition of an adjuvant to an existing vaccine, as has been done for influenza [18, 41-43], represents a potential and substantial benefit, where seroconversion rates and protective antibody titres in populations with reduced responsiveness (i.e. infants and the elderly) is an issue. Selection of an appropriate adjuvant will be influenced by the type of $\mathrm{CD} 4+\mathrm{T}$ cell response required for protection. In the context of available H1N1 influenza vaccine targets, there exists variable and relatively poor effectiveness which may be linked to the lack of antiviral Th1 responses. Two existing adjuvants MF59 and AS03 have been explored in this context. MF59, an immunological adjuvant that uses squalene, has been successfully formulated in licensed versions of the influenza vaccine worldwide, with significant increase in vaccine efficacy noted in clinical trials [41, 42]. MF59 appears to be particularly effective in APC recruitment and uptake, with subsequent drainage to the lymph nodes where an appropriate immune response is induced generating robust antibody titres consistent with protective efficacy ( $>40 \mathrm{HAI}$ ). ASO3 is another squalene-based adjuvant, used successfully in a pandemic H1N1 strain, again, immune responses are robust and confer levels indicative of protection, however, the persistence of the immune response particularly in infants and the elderly can differ and warrants further exploration in future vaccine candidates [43].

In a more recent study assessing adjuvant (GLA-SE; a TLR agonist) formulated with an H5N1 antigen, the authors highlighted the critical nature in the quality of $\mathrm{CD} 4+\mathrm{T}$ cell responses for protection and survival. The 
strategy here was aimed at inducing anti-viral Th1 responses through activation of TLR4 [10].

Our study highlights the attributes of Aluminium and, for the first time in an infectious disease model, MCT, in stimulating single-dose protection against a poorly immunogenic vaccine. Antibody responses are an important component in anti-influenza protection [44, 45]. While our study demonstrated the robust HAI titre generated by both groups receiving adjuvant candidate formulations (vs. unadjuvanted), it is the quality (functionality) of this response that requires further consideration in the context of what conditions increased antibody production facilitates improved protection. This would need to be considered to further assess its use in this and/or other models, or as part of a "mix and match" adjuvant systems approach. MCT's immunological (Th1; IgG) synergy with TLR mimetics has been established in allergy immunotherapy [46], while offering a unique platform for adsorption to antigen targets and/ or 2nd generation immunomodulators/adjuvants, as earlier described.

While the reported effectiveness of adjuvanting an influenza target are encouraging $[18,41]$; the properties of each adjuvant, alone, in the context of a human influenza vaccine target may be limiting.

However, the properties of MCT that lead to the reported effectiveness here, and elsewhere [23,33], permits further consideration in this and other vaccine targets - especially those found to be weakly immunostimulating, nonbiodegradable or those which bind poorly to existing antigens or when combined with other second generation immunomodulators/adjuvants. Further studies are now underway in different infectious disease models, while exploring the immunological signature of $\mathrm{MCT}$ powered to confer reproducibility.

\section{Conclusions}

The attributes of each adjuvant in stimulating singledose protection against a poorly immunogenic vaccine was demonstrated. The use of MCT alone or in "mix and match" adjuvant combinations for existing, new and/or emerging diseases warrants further exploration.

\section{Additional file}

Additional file 1: Weight loss analysis. (TIFF $88 \mathrm{~kb}$ )

\section{Abbreviations}

Alum: Alhydrogel adjuvant; AT: Allergy therapeutics plc; H1N1: Influenza A California/04/09 virus; IAV: Influenza A virus vaccines; MCT: Microcrystalline tyrosine adjuvant; TIV: Trivalent influenza vaccine; WHO: World Health Organisation

\section{Acknowledgments}

The authors acknowledge $\mathrm{BH}$ who, as Head of Preclinical Development and General Project Manager, was directly responsible for the conduct of the in-life study performed by Public Health England, PHE Porton, Porton Down, Salisbury, SP4 0JG, UK.

Funding

The research described in this paper was sponsored by Allergy Therapeutics plc, Dominion Way, Worthing, BN14 8SA, UK.

Availability of data and materials

Due to the proprietary nature of the materials used in the study, availability of data may be made available upon request.

\section{Authors' contributions}

$\mathrm{MDH}, \mathrm{NJS}$ and MAS conducted all aspects of MCT formulation experiments, design and supply of adjuvant material. ACM NJS and BH designed the study. ACM KEG and CP performed the experiments and analysed the data. $\mathrm{MDH}$ and $\mathrm{ACM}$ drafted the manuscript. All authors read and approved the final manuscript.

\section{Authors' information}

$\mathrm{MDH}$ is the Principal Scientist for Allergy Therapeutics Ltd.

\section{Competing interests}

The research described in this paper was sponsored by Allergy Therapeutics Ltd, Dominion Way, Worthing, BN14 8SA, UK. MD Heath, and MA Skinner are all employees of Allergy Therapeutics Ltd. The authors have no other relevant affiliations or financial involvement with any organization or entity with a financial interest in or financial conflict with the subject matter or materials discussed in the manuscript apart from those disclosed.

\section{Consent for publication}

N/A

\section{Ethics approval}

The experimental animal work described here was scrutinized and approved by the Animal Welfare and Ethical Review Body of Public Health England (Porton), as required by the UK Home Office Animals (Scientific Procedures) Act, 1986. The premises in which the work was conducted are approved under Home Office Certificate of Designation PCD70/1707.

\section{Publisher's Note}

Springer Nature remains neutral with regard to jurisdictional claims in published maps and institutional affiliations.

\section{Author details}

${ }^{1}$ Allergy Therapeutics Ltd, Dominion Way, West Sussex BN14 8SA, UK. ² Public Health England, PHE Porton, Porton Down, Salisbury SP4 0JG, UK. ${ }^{3}$ Present address: Kings College, Guys Campus, London SE1 3QD, UK.

Received: 9 March 2016 Accepted: 17 March 2017

Published online: 27 March 2017

\section{References}

1. Shanta M, Zimmer MD, Burke DS. Historical Perspective - Emergence of Influenza A (H1N1) Viruses. NEJM. 2009;361:279-85.

2. McGeogh D, Fellner P, Newton C. Influenza virus genome consists of eight distinct RNA species. Proc Natl Acad Sci U S A. 1976;73:3045-9.

3. Cox NJ, Subbarao K. Global epidemiology of influenza: Past and present Annu Rev Med. 2000;51:407-21.

4. Khandaker I, Suzuki A, Kamigaki T, Tohma K, Odagiri T, Okada T, et al. Molecular evolution of the hemagglutinin and neuraminidase genes of pandemic (H1N1) 2009 influenza viruses in Sendai, Japan, during 2009-2011. Virus Genes. 2013;47:456-66

5. Neumann G, Noda T, Kawaoka Y. Emergence and pandemic potential of swine-origin H1N1 influenza virus. Nature. 2009;459:931-8.

6. Butler D. Portrait of a year-old pandemic. Nature. 2010;464:1112-3.

7. Gilca R, Skowronski DM, Douville-Fradet M, et al. Mid-season estimates of influenza vaccine effectiveness against influenza A (H3N2) hospitalization in the elderly in Quebec, Canada, January 2015. PLoS One. 2015;10(7): e0132195.

8. Carrat F, Flahault A. Influenza vaccine: the challenge of antigenic drift. Vaccine. 2007;25:6852-62. 
9. Cowling BJ, Feng S, Finelli L, Steffens A, Fowlkes A. Assessment of influenza vaccine effectiveness in a sentinel surveillance network 2010-13. United States Vaccine. 2016;34:61-6.

10. Rockman S, Middleton DJ, Pearse MJ, Barr IG, Lowther S, Brown LE. Control of pandemic (H1N1) 2009 influenza virus infection of ferret lungs by non-adjuvantcontaining pandemic and seasonal vaccines. Vaccine. 2012;30:3618-23.

11. Park S-J, Kim E-H, Pascua PNQ, Kwon H-I, Lim G-J, Decano A, et al. Evaluation of heterosubtypic cross-protection against highly pathogenic $\mathrm{H} 5 \mathrm{~N} 1$ by active infection with human seasonal influenza A virus or trivalent inactivated vaccine immunization in ferret models. J Gen Virol. 2014;95:793-8.

12. Laurie KL, Carolan LA, Middleton D, Lowther S, Kelso A, Barr IG. Multiple infections with seasonal influenza $A$ virus induce cross-protective immunity against $A(H 1 N 1)$ pandemic influenza virus in a ferret model. J Infect Dis. 2010;202:1011-20.

13. Baras B, de Waal L, Stittelaar KJ, Jacob V, Giannini S, Kroeze EJBV, et al. Pandemic H1N1 vaccine requires the use of an adjuvant to protect against challenge in naïve ferrets. Vaccine. 2011;29:2120-6.

14. Gregorio EG, Rappuoli R. From empiricism to rational design: a personal perspective of the evolution of vaccine development. Nat Rev Immunol. 2014; 14:505-14

15. Awate $S$, Babiuk LA, Mutwiri G. Mechanism of action of adjuvants. Front Immunol. 2013:4:114

16. Chia M-Y, Hu AY-C, Tseng Y-F, Weng T-C, Lai C-C, Lin J-Y, et al. Evaluation of MDCK Cell-Derived Influenza H7N9 Vaccine Candidates in Ferrets. PLoS One. 2015;10

17. Pillet S, Racine T, Nfon C, Di Lenardo TZ, Babiuk S, Ward BJ, et al. Plantderived H7 VLP vaccine elicits protective immune response against H7N9 influenza virus in mice and ferrets. Vaccine. 2015;33:6282-9.

18. Clegg $\mathrm{CH}$, Roque R, Van Hoeven N, Perrone L, Baldwin SL, Rininger JA, et al. Adjuvant solution for pandemic influenza vaccine production. Proc Natl Acad Sci U S A. 2012;109:17585-90.

19. Baldrick $P$, Richardson D, Wheeler AW. Review of L-tyrosine confirming its safe human use as an adjuvant. J Appl Toxicol. 2002;22:333-44.

20. Rosewich M, Lee D, Zielen S. Pollinex Quattro: an innovative four injections immunotherapy in allergic rhinitis. Hum Vaccin Immunother. 2013;9:1523-31.

21. Wheeler AW, Moran DM, Robins BE, Driscoll A. L-Tyrosine as an Immunological Adjuvant. Int Arch Allergy Immunol. 1982;69:113-9.

22. Bell AJ, Heath MD, Hewings SJ, Skinner MA. The adsorption of allergoids and 3-O-desacyl-4'-monophosphoryl lipid $\mathrm{A}\left(\mathrm{MPL}^{\circledR}\right)$ to microcrystalline tyrosine $(\mathrm{MCT})$ in formulations for use in allergy immunotherapy. J Inorg Biochem. 2015;152:147-53.

23. DuBuske LM1, Frew AJ, Horak F, Keith PK, Corrigan CJ, Aberer W, Holdich T, von Weikersthal-Drachenberg KJ.Ultrashort-specific immunotherapy successfully treats seasonal allergic rhinoconjunctivitis to grass pollen. Allergy Asthma Proc. 2011; 32(3):239-47.

24. [http://otp.investis.com/clients/uk/allergy_therapeutics/rns/regulatory-story aspx?newsid=720112\&cid=1045]. Accessed 29 July 2016.

25. Marriott AC, Dove BK, Whittaker CJ, Bruce C, Ryan KA, Bean TJ, Rayner E, Pearson G, Taylor I, Dowall S, Plank J, Newman E, Barclay WS, Dimmock NJ, Easton AJ, Hallis B, Silman NJ, Carroll MW. Low dose influenza virus challenge in the ferret leads to increased virus shedding and greater sensitivity to oseltamivir. PLoS One. 2014:9

26. Bradford MM. A rapid and sensitive method for the quantitation of microgram quantities of protein utilising the principle of protein-dye binding. Anal Biochem. 1976;72:248-54.

27. Scherliess R, Ajmera A, Dennis M, Carroll MW, Altrichter J, Silman NJ, Scholz M, Kemter K, Marriott AC. Induction of protective immunity against H1N1 influenza $A(H 1 N 1) p d m 09$ with spray-dried and electron-beam sterilised vaccines in non-human primates. Vaccine. 2014;32:2231-40

28. Small PA, Waldman RH, Bruno JC, Gifford GE. Influenza infection in ferrets: role of serum antibody in protection and recovery. Infect Immun. 1976;13:417-24.

29. de Jong JC, Palache AM, Beyer WE, Rimmelzwaan GF, Boon AC, Osterhaus AD. Haemagglutination-inhibiting antibody to influenza virus. Dev Biol (Basel). 2003;115:63-73

30. Belser JA, Katz JM, Tumpey TM. The ferret as a model organism to study influenza A virus infection. Dis Model Mech. 2011;4:575-9.

31. van der Laan JW, Herberts C, Lambkin-Williams R, Boyers A, Mann AJ, Oxford J. Animal models in influenza vaccine testing. Expert Rev. Vaccines. 2008;7:783-93.

32. Marrack P, McKee AS, Munks MW. Towards an understanding of the adjuvant action of aluminium. Nat Rev Immunol. 2009;9:287-93.

33. Khong H, Sharma M, Dai Z, Singh M, Hailemichael Y, Overwijk W. L-tyrosine is a promising cancer vaccine adjuvant. J ImmunoTherapy of Cancer. 2015;3(2):1-1.
34. Clapp T, Siebert P, Chen D, Jones BL. Vaccines with aluminum-containing adjuvants: optimizing vaccine efficacy and thermal stability. J Pharm Sci. 2011;100:388-401

35. Lindblad EB. Aluminium compounds for use in vaccines. Immunol Cell Biol. 2004:82:497-505.

36. WHO Expert Committee on Biological Standardization Sixty-third report. Recommendations to assure the quality, safety and efficacy of tetanus vaccines (adsorbed) Replacement of Annex 2 of WHO Technical Report Series, No. 800, and Annex 5 of WHO Technical Report Series, No. 927.

37. O'Hagan DT, Fox CB. New generation adjuvants - From empiricism to rational design. Vaccine. 2015:B14-20.

38. Dimmock NJ, Dove BK, Scott PD, Meng B, Taylor I, Cheung L, Hallis B, Marriott AC, Carroll M, Easton AJ. Cloned defective interfering influenza virus protects ferrets from pandemic 2009 influenza A virus and allows protective immunity to be established. PLoS One. 2012;7:e49394.

39. Dimmock NJ, Dove BK, Meng B, Scott PD, Taylor I, Cheung L, Hallis B, Marriott AC, Carroll MW, Easton AJ. Comparison of the protection of ferrets against pandemic 2009 influenza A virus (H1N1) by 244 DI influenza virus and oseltamivir. Antivir Res. 2012;96:376-85.

40. Potter CW, Shore SL, McLaren C, Stuart-Harris C. Immunity to influenza in ferrets. II. Influence of adjuvants on immunization. Br J Exp Pathol. 1972;53: $168-79$

41. Podda A. The adjuvanted influenza vaccines with novel adjuvants: experience with the MF59-adjuvanted vaccine. Vaccine. 2001;21:2673-80.

42. O'Hagan DT, Ott GS, De Gregorio E, Seubert A. The mechanism of action of MF59 - an innately attractive adjuvant formulation. Vaccine. 2012;30(29): $4341-8$.

43. Roman F, Vaman T, Gerlach B, Markendorf A, Gillard P, Devaster JM. Immunogenicity and safety in adults of one dose of influenza A H1N1V 2009 vaccine formulated with and without AS03A-adjuvant: preliminary report of an observer-blind, randomised trial. Vaccine. 2010;28(7):1740-5

44. Gerhard W, Mozdzanowska K, Furchner M, Washko G, Maiese K. Role of the B-cell response in recovery of mice from primary influenza virus infection. Immunol Rev. 1997;159:95-103.

45. Waffarn EE, Baumgarth N. Protective B cell responses to flu-no fluke! J Immunol. 2011;186:3823-9.

46. Wheeler AW, Marshall JS, Ulrich JT. A Th1-inducing adjuvant, MPL, enhances antibody profiles in experimental animals suggesting it has the potential to improve the efficacy of allergy vaccines. Int Arch Allergy Immunol. 2001; 126(2):135-9.

\section{Submit your next manuscript to BioMed Central and we will help you at every step:}

- We accept pre-submission inquiries

- Our selector tool helps you to find the most relevant journal

- We provide round the clock customer support

- Convenient online submission

- Thorough peer review

- Inclusion in PubMed and all major indexing services

- Maximum visibility for your research

Submit your manuscript at www.biomedcentral.com/submit 